\title{
O direito de ir e vir: a acessibilidade do transporte público ${ }^{1}$
}

\author{
Ana Flávia Rodrigues Vieira, Alessandra Cavalcanti, Alysson Lourenço Alves \\ Universidade Federal do Triângulo Mineiro - UFTM, Uberaba, MG, Brasil.
}

\begin{abstract}
Resumo: O transporte público coletivo possibilita o acesso a diferentes locais e influencia o deslocamento e a mobilidade de pessoas dentro de uma cidade. Indivíduos com deficiência ou mobilidade reduzida necessitam de ações que agregam planejamento e execução de medidas que tornem o transporte público acessível. Objetivou-se descrever a acessibilidade do transporte coletivo urbano no município de Uberaba-MG, na opinião das pessoas com deficiência e mobilidade reduzida. Os dados foram coletados por entrevista semiestruturada junto a sete usuários de transporte coletivo da cidade que possuem deficiência e são associados à instituição local voltada para a reabilitação de pessoas com deficiência física. O tratamento dos dados ocorreu pela técnica de análise de conteúdo temática. Os resultados sobre a definição de acessibilidade apontaram-na como o direito que equipara as pessoas com deficiência às sem deficiência, permitindo autonomia para ir e vir, bem como independência para a locomoção; e sobre a acessibilidade dos ônibus, foi apontado pelos participantes como dependente de determinadas variáveis, como pessoal técnico e conservação de equipamentos. Conclui-se que, na opinião das pessoas com deficiência e mobilidade reduzida, participantes do estudo e que são passageiros de transporte coletivo urbano (ônibus) no município de Uberaba-MG, a acessibilidade ainda é falha e precisa de adequações.
\end{abstract}

Palavras-chave: Equidade no Acesso, Saúde da Pessoa com Deficiência, Transportes.

\section{The right to come and go: public transport accessibility}

\begin{abstract}
The public transportation allows access to different places and affects people dislocation and mobility within a city. People with disabilities or reduced mobility require actions that combine planning and execution of measures to make public transportation more accessible. This study aimed to describe the urban public transport accessibility in the city of Uberaba/MG according to people with disabilities and reduced mobility. Data was collected by semi-structured interviews along with seven city public transport users with disabilities and are associated to the local institution focused on the rehabilitation of people with physical disabilities. Data processing was performed using the thematic content analysis technique. The results on the accessibility definition showed it as the right that levels people with and without disabilities, allowing autonomy to come and go as well as independence for locomotion. Regarding buses accessibility the participants pointed out the dependency on certain variables such as technical personnel and equipment conservation. We conclude that in the opinion of people with disabilities and reduced mobility there is still a lack of accessibility and needs to be adjusted.
\end{abstract}

Keywords: Equity in Access, Health of the Disabled, Transportation.

Autor para correspondência: Alessandra Cavalcanti, Departamento de Terapia Ocupacional, Unidade Centro Educacional, Universidade Federal do Triângulo Mineiro, Av. Getúlio Guaritá, s/n, 3. Piso, Sala 329, CEP 38025-440, Uberaba, MG, Brasil, e-mail: lelecavalcanti@yahoo.com.br; lita@to.uftm.edu.br

Recebido em Dez. 16, 2014; $1^{\text {a }}$ Revisão em Mar. 6,2015; Aceito em Ago. 3, 2015. 


\section{Introdução}

O transporte público coletivo é concebido para possibilitar aos usuários acesso a diferentes locais, como, por exemplos, o do trabalho, o do domicílio e o de lazer, em consonância com um dos direitos e garantias fundamentados na constituição brasileira, o de 'ir e vir' (BRASIL, 2008c). Com a função de interligar as pessoas em diversos locais, oportuniza atividades de comércio e crescimento da região, e consequentemente viabiliza a ocupação dos espaços urbanos e articula pessoas, tarefas e locais, tornando a população, de certa forma, dependente deste meio de transporte (AZAMBUJA, 2002).

No conjunto de uma cidade, o transporte público é um dos itens que irão influenciar na acessibilidade das pessoas para efetivar o deslocamento e a mobilidade para onde se deseja (CAVALCANTI et al., 2013). Além das características do espaço físico, que envolve a presença ou não de barreiras, entraves ou obstáculos, a adequação da frota de transporte coletivo para uso autônomo e seguro por todos também é uma das condições que influenciarão na mobilidade das pessoas (BRASIL, 2008b).

Evidenciando a possibilidade de utilizar o transporte público e entrar em qualquer local, as pessoas com deficiência ou com restriçáo de mobilidade necessitam de açôes que agregam planejamento, contratação e execuçáo de medidas para tornar os espaços com acesso universal, ou seja, para todos (BRASIL, 2008a).

Assim, dentre essas açóes, no ano de 2000, o governo brasileiro, com a Lei n. ${ }^{\circ} 10.048$, decretou, dentre outras providências, que as empresas públicas de transporte e as concessionárias de transporte coletivo passariam a ter nos veículos lugar reservado e identificado para as pessoas com deficiência, idosos, gestantes e pessoas com criança no colo; foi decretado também que os veículos produzidos um ano após seu sancionamento seriam planejados para facilitar a acessibilidades das pessoas ao seu interior (LIMA, 2007). Ainda, assegurou um prazo em torno de seis meses para aqueles veículos que já estavam em circulação para efetivação de adaptações voltadas a garantir o acesso ao veículo por todas as pessoas (BRASIL, 2012).

Portanto, independentemente da capacidade de locomoçẫo do seu usuário, um veículo de transporte coletivo urbano, a partir daquele ano, deveria garantir acesso ao seu interior, estando livre de barreiras em suas portas de entrada e saída, e mantendo autonomia e segurança para aqueles que dele fazem uso (BRASIL, 2008a).
Apesar de não haver um único modelo para transporte coletivo acessível, pois cada regiáo tem suas peculiaridades e características físicas das vias, assim como existem variaçóes de equipamentos e de modelos operacionais, o uso do transporte público é normatizado pela ABNT NBR 14022/06 (ASSOCIAÇÃO..., 2006).

Esta norma institui parâmetros e critérios técnicos de acessibilidade para transporte coletivo de usuários em localidades urbanas, alinhada com as proposiçóes do desenho universal. A intenção é proporcionar acessibilidade ou acessibilidade assistida, com segurança e autonomia, no veículo do sistema de transporte público.

Entende-se acessibilidade como a

[...] condiçấo para utilizaçấo, com segurança e autonomia, total ou assistida, dos serviços de transporte coletivo de passageiros, por pessoa com deficiência ou mobilidade reduzida [...], enquanto acessibilidade assistida é esta condição com assistência de profissional capacitado para atender o passageiro com deficiência ou mobilidade reduzida (ASSOCIAÇÃO..., 2006, p. 2).

Passados mais de dez anos após a promulgação da Lei n.o 10.048/00 e compreendendo a importância de um transporte público coletivo acessível em consonância com o Ministério das Cidades, que registra a necessidade de "[...] análises de adequação tecnológica para cada regiáo, cada via ou cada linha de transporte da cidade [...]" (BRASIL, 2008c, p. 65), um mapeamento no município subsidiaria a atual situação acerca da temática.

Assim, este trabalho tem como objetivo descrever a acessibilidade do transporte coletivo urbano (ônibus) no município de Uberaba-MG, na opinião das pessoas com deficiência e mobilidade reduzida.

\section{Procedimentos metodológicos}

\subsection{Tipo de estudo e aspectos éticos}

Este trabalho possui natureza qualitativa e constitui-se de um estudo exploratório do tipo transversal descritivo (SAMPIERI; COLLADO; LUCIO, 2006). O projeto de pesquisa foi aprovado pelo Comitê de Ética em Pesquisa da Universidade Federal do Triângulo Mineiro (CEP/UFTM) pelo parecer n. ${ }^{0} 2.385$ de 2012. Todos os participantes consentiram a participaçáo na pesquisa assinando o Termo de Consentimento Livre e Esclarecido no momento da coleta de dados. 


\subsection{Participantes e local}

Para este estudo, foram incluídos usuários de transporte coletivo de passageiros da cidade de Uberaba-MG, que possuem deficiência e são associados a uma instituição local voltada para a reabilitação de pessoas com deficiência física. Os critérios de inclusão foram ser indivíduo com deficiência física ou com mobilidade reduzida, com idade igual ou superior a 18 anos, e utilizar o transporte coletivo urbano (ônibus) da cidade de Uberaba-MG pelo menos uma vez na semana para o deslocamento entre seu domicílio e a instituição. Se o associado náo se encontrava na cidade no período estabelecido de coleta de dados ou se o transporte utilizado no trajeto domicílio-instituiçâo fosse realizado por meio de van própria da instituição ou outro meio (carro particular, por exemplo), o participante seria excluído do estudo. A pesquisa ocorreu dentro do ônibus durante o percurso de deslocamento entre seu domicílio e a instituição, de acordo com a disponibilidade de cada participante. O percurso iniciava no ponto de embarque de uso habitual da pessoa e terminava no ponto de parada próximo à instituição. O tempo médio de cada entrevista foi de dez minutos e a média do percurso foi de uma hora.

\subsection{Procedimento para a coleta de dados}

Para a coleta, foi constituída uma equipe de dois pesquisadores, um para aplicação dos instrumentos de coleta dos dados dentro do ônibus, junto ao participante durante o deslocamento do trajeto domicílio-instituição, e outro para acompanhamento externo do veículo, responsável pelo suporte do percurso.

A coleta de dados ocorreu em dias semanais entre os meses de novembro e dezembro de 2013, após contato inicial com a instituição e conhecimento de que nove associados realizavam o deslocamento utilizando o ônibus urbano como meio de transporte.

Procedeu-se à seleção dos participantes de acordo com os critérios de inclusão e exclusão supramencionados, e os usuários foram contatados por telefone e convidados a participar da pesquisa. Dos associados identificados pelos critérios, dois não participaram por não se encontrarem na cidade no período da coleta; portanto, sete pessoas constituíram a amostra. O Termo de Consentimento Livre e Esclarecido (TCLE) foi lido pelo primeiro autor no início do trajeto e assinado em sequência, antes do pesquisador e do participante entrarem no ônibus para o deslocamento no trecho domicílio-instituição.

\subsection{Instrumento de coleta de dados}

O instrumento utilizado foi uma entrevista semiestruturada idealizada pelas autoras. Tal técnica permitiu o livre discurso para os respondentes (VIEIRA, 2009). No roteiro de entrevista, constavam: a caracterizaçáo dos participantes quanto a idade, gênero e diagnóstico clínico; a caracterização do serviço de transporte público utilizado pelos participantes referente à quantidade de ônibus que o usuário utilizava no trajeto entre domicílio-instituição e quem assistia a acessibilidade. A entrevista também continha duas questôes abertas: (i) o que é acessibilidade; (ii) qual a opinião do usuário em relação à acessibilidade do veículo em uso. Antes da aplicação da entrevista, um pré-teste visando ao aperfeiçoamento desse instrumento foi realizado, buscando-se examinar se este respondia ao objetivo do estudo. Após esse pré-teste, observou-se a necessidade de acrescentar uma questáo que identificasse o tipo de equipamento utilizado para a locomoção do usuário com deficiência.

\subsection{Análise dos dados}

As entrevistas foram gravadas em meio digital, transcritas na íntegra e posteriormente analisadas sistematicamente por equivalência do tema, agregando-se as similitudes das características em unidades. Em seguida, procedeu-se à categorização dos achados por meio da técnica de análise de conteúdo proposta por Bardin (2010), descrevendo-as em termos de frequência de aparição.

\section{Resultados e discussão}

As características dos participantes (idade, gênero, diagnóstico clínico e equipamento utilizado para a locomoção) podem ser observadas na Tabela 1 .

A idade média dos participantes foi de 28,86 anos $( \pm 8,80)$, sendo a maior idade 40 anos e a menor idade 18 anos, havendo equidade de usuários de ambos os gêneros. Em relação ao diagnóstico clínico, três possuem doença muscular progressiva, dois tiveram doença infecciosa viral, um teve paralisia cerebral e outro tem má formaçáo congênita. Com relação ao equipamento utilizado para a locomoçáo, cinco usuários utilizam cadeira de rodas motorizada, um usa cadeira de rodas manual e outro náo utiliza equipamento (deambula independente com dificuldade).

Quanto às características do serviço de transporte público utilizado pelos participantes (quantidade de ônibus que utilizam no trajeto entre domićlilio-instituição e quem os assiste na acessibilidade), foi verificado que 
Tabela 1. Caracterização dos participantes da pesquisa $(\mathrm{n}=7)$.

\begin{tabular}{cccll}
\hline Participante & Idade & Gênero & \multicolumn{1}{c}{ Diagnóstico Clínico } & \multicolumn{1}{c}{ Equipamento } \\
\hline Usuário 01 & 40 anos & Feminino & Doença Muscular Progressiva & Cadeira de rodas motorizada \\
Usuário 02 & 18 anos & Feminino & Má formação Congênita & Cadeira de rodas manual \\
Usuário 03 & 21 anos & Masculino & Doença Muscular Progressiva & Cadeira de rodas motorizada \\
Usuário 04 & 32 anos & Masculino & Doença Infecciosa Viral & Cadeira de rodas motorizada \\
Usuário 05 & 30 anos & Feminino & Paralisia Cerebral & Cadeira de rodas motorizada \\
Usuário 06 & 22 anos & Masculino & Doença Muscular Progressiva & Cadeira de rodas motorizada \\
Usuário 07 & 39 anos & Feminino & Doença Infecciosa Viral & Sem equipamento \\
\hline
\end{tabular}

quatro usuários tomam uma linha de ônibus para se deslocar até a instituição e os demais utilizam duas. Todos são assistidos pelo motorista para adentrar no transporte, sendo o posicionamento na área reservada para cadeira de rodas e a colocaçáo dos equipamentos de proteção (sistema de ancoragem e cinto de segurança) realizados pelos próprios participantes deste estudo.

\subsection{Categoria 1- "Acessibilidade é..."}

Com relação às questóes abertas, na primeira categoria de análise, denominada "Acessibilidade é...", foram relatados os diferentes aspectos que definem a acessibilidade sob a visão dos usuários. De forma geral, eles descreveram que a acessibilidade é (i) direito, (ii) poder ir e vir, e (iii) uma fácil locomoção, pontuando-a como o direito que os equiparam às pessoas sem deficiência, permitindo autonomia para ir e vir, bem como independência para a locomoção. A acessibilidade foi relatada como direito constitucional que deveria ser garantido: "[...] direito da gente andar na rua como uma pessoa normal" (P6) e que, por vezes, não é exercido no contexto da cidade: "[...]É um direito da gente, só que muitas vezes não acontece. Se não cobrar num... as coisas não sai" (P4).

Souza e Gitahy (2012) abordam a acessibilidade para as pessoas com deficiência como direito fundamental responsável pela inclusão social, imprescindível para liberdade e locomoção dos participantes. Sob a perspectiva dos dirigentes, a acessibilidade é compreendida como parte da política pública de mobilidade urbana, que efetiva os direitos fundamentais de qualquer cidadão (BRASIL, 2008c).

A regulamentaçáo de diretrizes, como as Leis n. ${ }^{\circ}$ 10.048/00 e n. ${ }^{\circ} 10.098 / 00$ (BRASIL, 2000a, 2000b), concretiza ações que vão auxiliar na equiparação de oportunidades para as pessoas com deficiência, por exemplo, e conduzir, portanto, para a realizaçáo do direito constitucional (LIMA, 2007).

Os participantes também enfatizaram que a acessibilidade é a possibilidade de estarem e utilizarem os diferentes lugares que compóem o cenário de uma cidade: “[...]Acessibilidade [...]é você poder ir e vir onde você quiser, a qualquer hora" (P3), sem ter de precisar da ajuda de terceiros, tendo, portanto, autonomia, liberdade e independência: "É você poder ir nos lugares que você quer sem depender de outras pessoas para te ajudar pra isso" (P1). Assim como relataram ser um maneira de deslocamento e permanência nos espaços: "[...] seria um... um fácil jeito de se locomover e se habituar a algum lugar" (P2).

Toda pessoa tem o direito de ir e vir, sendo de responsabilidade dos gestores públicos instituírem açôes para inclusão, dentre as quais a criação de programas de gerenciamento da acessibilidade (FERREIRA; FOLHA; TOBIAS, 2013). A ausência de infraestrutura e serviços adequados restringe a oportunidade de utilizaçáo da cidade para parte da população (BRASIL, 2008a). A terapia ocupacional apoia o cumprimento destas açóes de modo a garantir inclusão e acessibilidade destes indivíduos em todos os aspectos da vida cotidiana, proporcionando-lhes maior independência, autonomia e efetivação de seus papéis ocupacionais (SALLES et al., 2010).

Deficientes físicos apresentam diferentes necessidades perante o acesso a determinados locais. A equiparação de oportunidades para a mobilidade torna possível a acessibilidade nestes ambientes, em que equipamentos assistivos associados a ambientes adaptados ampliam a capacidade funcional, favorecendo o desempenho de papéis ocupacionais nas áreas de trabalho, educação, lazer, autocuidado e participação social (COOK; POLGAR, 2008).

A mobilidade na comunidade para a terapia ocupacional é uma atividade instrumental de vida diária, que demanda interaçáo da pessoa com o ambiente (FERREIRA; FOLHA; TOBIAS, 2013). De acordo com a Associaçáo Americana de Terapia Ocupacional (ASSOCIAÇÃO..., 2014, p. S19) a mobilidade pode ser definida como

[...] mover-se na comunidade e usar o transporte público ou privado, como dirigir, caminhar, andar de bicicleta ou acessar e locomover-se através de ônibus, táxi ou outros sistemas de transporte. 


\subsection{Categoria 2- "Acessibilidade do veículo"}

$\mathrm{Na}$ segunda categoria de análise, "Acessibilidade do veículo", a adequação do ônibus em uso durante a entrevista e que rotineiramente era utilizado para o deslocamento entre o domicílio e a instituiçáo foi apontada como dependente de determinadas variáveis, como pessoal técnico e conservação de equipamentos. Os participantes exemplificaram essa dependência pontuando sobre a falta de manutençáo dos equipamentos, que são determinantes para o acesso ao interior do veículo, relatando a atual situação: "Poderiam ser melhor. Porque muitas vezes embora todos os ônibus estão adaptados, muitos ainda estão com defeito[...]. A manutençáo poderia ser melhor" (S1) ou "[...]É ruim quando o elevador não quer funcionar, né?! Ai, quando não quer funcionar o que acontece é que você tem que esperar o próximo. E se tiver chovendo?" (S5)

De acordo com o Art. 4. ${ }^{\circ}$, Inciso III, do Conselho Nacional de Trânsito, Resolução do CONTRAN n. ${ }^{\circ}$ 469/2013 (BRASIL, 2013), fica estabelecido:

Os equipamentos destinados à acessibilidade, como plataforma elevatória veicular, rampa de acesso e cadeira de transbordo, bem como o sistema de ancoragem e cintos de segurança, quando aplicáveis nos veículos, deverão estar em perfeito estado de conservação e funcionamento.

A responsabilidade de gerenciamento e fiscalização do transporte público urbano de passageiros é do município e devem ser exercidos com participação de diferentes integrantes com visóes variadas, que atendam as necessidades da população local (BRASIL, 2008c).

Os usuários também relataram a relação da acessibilidade com o atendimento e a preparação técnica dos motoristas condutores do veículo em uso naquele momento: "A acessibilidade do veículo depende da pessoa e do motorista, né?! Depende do ponto de ônibus, depende se estiver chovendo, ele [o motorista] não para o ônibus [...]" (S3). "O motorista não está bem preparado para manusear o elevador e a gente. Acaba ficando um constrangimento [...]" (S6).

Um transporte coletivo acessível não depende apenas da formulação de leis sobre equipamentos e mobiliários adequados. Também é de grande relevância a açấo de condutores (motoristas e cobradores). A falta de preparo dos condutores em transportar pessoas com deficiência aponta a importância de treinamento contínuo, que leve em consideração a operacionalização das plataformas elevatórias e o preparo psicossocial voltado a um tratamento mais adequado (RABELO, 2008)

De acordo com a pesquisa feita por Cavalcanti et al. (2013), todos os motoristas e cobradores do transporte público de Uberaba-MG recebem treinamento para a utilização dos equipamentos destinados à acessibilidade; no entanto, a capacitação é deficitária, ressaltando a necessidade de novos treinamentos com intuito de ampliar a compreensão e a efetivação da acessibilidade neste serviço prestado.

\section{Conclusão}

Conclui-se que, na opinião das pessoas com deficiência e mobilidade reduzida, que são passageiros de transporte coletivo urbano (ônibus) no município de Uberaba-MG, a acessibilidade ainda é falha e precisa de adequações.

A falta da manutenção periódica inviabiliza o acesso das pessoas com deficiência ou mobilidade reduzida aos veículos, repercutindo na utilizaçáo dos equipamentos existentes. Com relação à capacitação e ao treinamento dos motoristas e cobradores, cujo preparo deficitário limita o acesso às pessoas com deficiência ou mobilidade reduzida, mostra-se fundamental identificar elementos, modelos e práticas gerenciais consistentes que permitam melhorias referentes à capacitaçáo de motoristas e cobradores para um trabalho mais humanizado, resultando em melhoria de qualidade dos serviços urbanos prestados.

No entanto, é reconhecido o esforço das ações do governo para a acessibilidade; porém, a falta de fiscalização e gerenciamento dificulta a acessibilidade.

Uma vez que a rota avaliada pelos pesquisadores $\mathrm{diz}$ respeito às linhas de transporte público que realizam o trajeto bairro-instituição de deficientes físicos associados, pode-se inferir que as linhas analisadas são as que comumente utilizam os dispositivos de adaptação e necessitam dos motoristas e cobradores na utilização destes equipamentos. Nesse sentido, questionam-se quais seriam os problemas encontrados nas outras linhas de transporte público que servem as pessoas com deficiência na promoção da mobilidade na cidade.

Por fim, o presente artigo demonstra que novas pesquisas devem ser desenvolvidas a fim de retratar as reais condiçóes dos veículos em circulação referentes aos parâmetros e critérios técnicos de acessibilidade, e às proposiçóes do desenho universal. 


\section{Referências}

ASSOCIAÇÃO AMERICANA DE TERAPIA OCUPACIONAL - AOTA. Occupational therapy practice framework: domain and process. The American Journal of Occupational Therapy, Bethesda, v. 68, n. SE 1, p. S1-S48, 2014. http://dx.doi.org/10.5014/ajot.2014.682006.

ASSOCIAÇÃO BRASILEIRA DE NORMAS TÉCNICAS - ABNT. NBR 14022: Acessibilidade em veículos de características urbanas para o transporte coletivo de passageiros. Rio de Janeiro, 2006.

AZAMBUJA, A. M. V. Análise de eficiência na gestão do transporte urbano por ônibus em municípios brasileiros. 2002. 410 f. Tese (Doutorado em Engenharia de Produçáo) - Universidade Federal de Santa Catarina, Florianópolis, 2002.

BARDIN, L. Análise de conteúdo. Lisboa: Ediçōes 70, 2010.

BRASIL. Lei no 10.048 de 08 de novembro de 2000. Dá prioridade de atendimento às pessoas que especifica, e dá outras providências. Diário Oficial [da] República Federativa do Brasil, Brasília, DF, 8 nov. 2000a. Disponível em: <http://www.planalto.gov.br/ccivil_03/leis/L10048. htm>. Acesso em: 13 jan. 2014.

BRASIL. Lei no 10.098 de 19 de dezembro de 2000. Estabelece normas gerais e critérios básicos para a promoção da acessibilidade das pessoas portadoras de deficiência ou com mobilidade reduzida, e dá outras providências. Diário Oficial [da] República Federativa do Brasil, Brasília, DF, 20 dez. 2000b. Disponível em: <http:// www.planalto.gov.br/ccivil_03/leis/L10098.htm>. Acesso em: 13 jan. 2014.

BRASIL. Ministério das Cidades. Implementação de politicas municipais de acessibilidade. Brasília, 2008a. (Brasil Acessivel: Programa Brasileiro de Acessibilidade Urbana, 4).

BRASIL. Ministério das Cidades. Implementação do Decreto n5296/04 para a construção da cidade acessivel. Brasília, 2008b. (Brasil Acessível: Programa Brasileiro de Acessibilidade Urbana, 3).

BRASIL. Ministério das Cidades. Implantação de sistemas de transporte acessivel. Brasília, 2008c. (Brasil Acessível: Programa Brasileiro de Acessibilidade Urbana, 5).
BRASIL. Secretaria de Direitos Humanos. Pessoa com deficiência legislação federal. Brasília, 2012.

BRASIL. Resolução CONTRAN no 469 de 11 de dezembro de 2013. Altera dispositivos e os anexos da resolução CONTRAN no 402, de 26 de abril de 2012. Diário Oficial [da] República Federativa do Brasil, Brasília, DF, 11 dez. 2013. Disponível em: <https://www. legisweb.com.br/legislacao/?id=263251 >. Acesso em: 27 jan. 2014.

CAVALCANTI, A. et al. Acessibilidade em transporte coletivo urbano na perspectiva dos motoristas e cobradores. Cadernos de Terapia Ocupacional da UFSCar, São Carlos, v. 21, n. 1, p. 19-24, 2013. http://dx.doi. org/10.4322/cto.2013.004.

COOK, A. M.; POLGAR, J. Assistive technology: principles and practice. Philadelphia: Elsevier, 2008.

FERREIRA, E. F. B.; FOLHA, O. A. A. C.; TOBIAS, M. S. G. Avaliação da percepção sobre o ambiente de circulaçấo: a acessibilidade centrada no usuário. Cadernos de Terapia Ocupacional da UFSCar, São Carlos, v. 21, n. 1, p. 25-33, 2013.

LIMA, N. M. Pessoa portadora de deficiência: Legislaçáo Federal Básica. Brasília: Secretaria Especial de Direitos Humanos, 2007.

RABELO, G. B. Avaliação da acessibilidade de pessoas com deficiência fisica no transporte coletivo urbano. 2008. 195 f. Dissertação (Mestrado em Engenharia Civil) Universidade Federal de Uberlândia, Uberlândia, 2008.

SALLES, B. G. et al. A acessibilidade arquitetônica interfere na usabilidade de indivíduos com mobilidade reduzida? Revista de Terapia Ocupacional da Universidade de São Paulo, São Paulo, v. 21, n. 1, p. 83-88, 2010.

SAMPIERI, R. H.; COLLADO, C. F.; LUCIO, P. B. Metodologia de pesquisa. São Paulo: McGraw Hill, 2006.

SOUZA, C. M. A.; GITAHY, R. R. C. Acessibilidade das pessoas com deficiência. Interfaces da Educação, $\mathrm{Pa}-$ ranaíba, v. 3, n. 9, p. 16-29, 2012.

VIEIRA, S. Como elaborar questionários. São Paulo: Atlas, 2009.

\section{Contribuição dos Autores}

Ana Flávia Rodrigues Vieira: elaborou o projeto de pesquisa, coletou e analisou os dados, e redigiu o texto. Alessandra Cavalcanti: orientou a concepção do projeto de pesquisa, auxiliou na coleta dos dados, orientou a análise dos dados e a redaçáo do texto. Alysson Lourenço Alves: foi responsável pela revisáo do texto. Todos os autores aprovaram a versão final do artigo.

\section{Notas}

${ }^{1}$ Artigo decorrente do Trabalho de Conclusão de Curso (TCC) do Curso de Terapia Ocupacional da Universidade Federal do Triângulo Mineiro (UFTM) - aprovado pelo Comitê de Ética em Pesquisa em Seres Humanos da UFTM, de acordo com o parecer n. 2385 de 2012. 